\title{
Dehydroepiandrosterone induces growth arrest of hepatoma cells via alteration of mitochondrial gene expression and function
}

\author{
HUNG-YAO HO ${ }^{1 *}$, MEI-LING CHENG ${ }^{1,2,4^{*}}$, HSIN-YU CHIU ${ }^{1}$, \\ SHIUE-FEN WENG ${ }^{1}$ and DANIEL TSUN-YEE CHIU ${ }^{1,3,4}$ \\ ${ }^{1}$ Graduate Institute of Medical Biotechnology and Department of Medical Biotechnology and Laboratory Science, \\ ${ }^{2}$ Center for Gerontological Research, ${ }^{3}$ Graduate Institute of Basic Medical Sciences, Chang Gung University; \\ ${ }^{4}$ Department of Clinical Pathology, Chang Gung Memorial Hospital, Kwei-san, Tao-yuan, Taiwan
}

Received April 24, 2008; Accepted June 30, 2008

DOI: 10.3892/ijo_00000084

\begin{abstract}
DHEA is known to have anti-proliferative effect. The mechanism is not completely understood. We investigated the mechanism underlying DHEA-induced growth arrest of hepatoma cells. Growth inhibition was associated with increased G6PD activity, and insensitive to reversal by mevalonate. Thus, DHEA does not act via inhibition of G6PD and HMGR. Instead, growth stagnation was accompanied by reduced expression of nucleus-encoded mitochondrial genes; morphological and functional alterations of mitochondria; and depletion of intracellular ATP. Conversely, pyruvate supplementation alleviated DHEA-induced growth inhibition. It is likely that DHEA suppresses cell growth by altering mitochondrial gene expression, morphology and functions.
\end{abstract}

\section{Introduction}

DHEA is an endogenous steroid secreted by adrenal cortex, gastrointestinal tract, gonads, and brain (1). Together with its

Correspondence to: Dr Hung-Yao Ho or Dr Daniel Tsun-Yee Chiu, Graduate Institute of Medical Biotechnology and Department of Medical Biotechnology and Laboratory Science, Chang Gung University, 259 Wen-Hua 1st Road, Kwei-san, Tao-yuan, Taiwan, R.O.C. E-mail: hoh01@mail.cgu.edu.tw; dtychiu@mail.cgu.edu.tw

${ }^{*}$ Contributed equally

Abbreviations: ATP, adenosine triphosphate; ATP5O, ATP synthase oligomycin sensitivity conferral protein; COX5A, cytochrome c oxidase subunit Va; DHEA, dehydroepiandrosterone; G6PD, glucose-6-phosphate dehydrogenase; GAPDH, glyceraldehyde 3phosphate dehydrogenase; HMGR, 3-hydroxy-3-methylglutaryl CoA reductase; MVA, mevalonate; NDUFA9, NADH dehydrogenase (ubiquinone) 1 alpha subcomplex 9; OXPHOS, oxidative phosphorylation; Rb, retinoblastoma; RT-PCR, reverse transcriptionpolymerase chain reaction; SDHA, succinate dehydrogenase complex subunit A; UQCRFS1, ubiquinol-cytochrome c reductase Rieske iron-sulfur polypeptide 1

Key words: steroid, hepatoma, mitochondrion sulfate form, DHEA is the most abundant steroid in human circulation. Plasma concentration of DHEA increases during adolescence; reaches its maximum at around 25 years of age; and decreases afterwards to $10 \%$ of adolescent level by the age of 80 (2). DHEA is a multifunctional hormone with such beneficial effects as antiobesity $(3,4)$, hypoglycemia (4-6); anti-atherosclerosis $(7,8)$, as well as anti-aging and memoryenhancing effect on brain (9). It has been reported that low DHEA levels correlated with increased risks of tumorigenesis $(10,11)$. DHEA has been shown to prevent spontaneous tumorigenesis in p53-knockout mice (12), and to inhibit chemically induced carcinogenesis in liver (13-15), colon (16), lung (17), and breast (18). DHEA exerts antiproliferative effect on a number of cell lines in vitro and in vivo $(19,20)$.

The mechanism of the growth inhibitory action of DHEA remains unclear. Several mechanisms have been proposed. As an uncompetitive inhibitor of G6PD, DHEA suppresses the rate-limiting step of pentose phosphate pathway, and reduces the supply of NADPH and ribose-5-phosphate. Both of these products are necessary for cell growth (21). However, the involvement of G6PD in growth inhibition by DHEA is questionable (22-25). Additionally, DHEA may inhibit 3-hydroxy-3-methylglutaryl CoA reductase (HMGR) (26), the rate-limiting enzyme in cholesterol biosynthesis. Inhibition of this enzyme reduces the flux through de novo cholesterol biosynthesis, with subsequent decrease in level of its immediate product mevalonic acid (MVA). Being a precursor of farnesyl diphosphate, the abundance of MVA determines the degree of farnesylation of Ras and activation of mitogen-activated protein kinase pathway (27). Moreover, DHEA may affect bioenergetic metabolism. DHEA has hypoglycemic and anti-diabetic effect in animal models (4-6). It has been reported that DHEA regulates the expression of enzymes involved in glucose metabolism $(28,29)$. Increased glucose uptake has also been observed in DHEA-treated cells $(29,30)$.

To delineate the mechanism underlying growth suppressive effect of DHEA, we employed human hepatoma cell line Hep G2 in the present study. We show that DHEA inhibited cell growth in time- and dose-dependent manner. DHEA did not act through inhibition of G6PD and HMGR. Instead, growth inhibition was associated with reduced expression 
of nucleus-encoded mitochondrial genes; changes in mitochondrial morphology and function; and ATP depletion. Supplementation with pyruvate mitigated the growth inhibition by DHEA. Our findings support the notion that the growth suppressive effect of DHEA may be attributed to changes in mitochondrial gene expression and functions.

\section{Materials and methods}

Reagents. Unless stated otherwise, DHEA and all other chemicals were obtained from Sigma (St. Louis, MO). Dulbecco's modified Eagle's medium (DMEM), fetal calf serum (FCS), penicillin, streptomycin, amphotericin, and trypan blue were purchased from Invitrogen (Carlsbad, CA). 5,5',6,6'-tetrachloro-1,1',3,3'-tetraethylbenzimidazolcarbocyanine iodide (JC-1) and Hoechst dye were available from Invitrogen.

Cell culture. Hep G2 cells were obtained from American Type Culture Collection (ATCC catalog no.: HB-8065), and were maintained in Dulbecco's modified Eagle's medium (DMEM) $/ 10 \%$ fetal calf serum at $37^{\circ} \mathrm{C}$ in a humidified atmosphere of $5 \% \mathrm{CO}_{2}$. For DHEA treatment, $2 \times 10^{5}$ cells were incubated with 100 or $200 \mu \mathrm{M}$ DHEA for the indicated period. Cell number was determined by cell counting as well as neutral red assay. The neutral red assay was performed according to a modification of the previously described method (31). Briefly stated, neutral red solution was added to cells at a final concentration of $0.033 \%(\mathrm{w} / \mathrm{v})$. The cells were then incubated at $37^{\circ} \mathrm{C}$ in a humidified atmosphere of $5 \% \mathrm{CO}_{2}$ for $2 \mathrm{~h}$. The medium was aspirated very gently, and the monolayer was rinsed with fixative $\left(0.1 \% \mathrm{CaCl}_{2}\right.$ in $0.5 \%$ formaldehyde). After removal of fixative, the incorporated dye was then extracted in $1 \%$ acetic acid in $50 \%$ ethanol for $10 \mathrm{~min}$. The absorbance of extracted dye was measured at $540 \mathrm{~nm}$. The absorbance at a reference wavelength of $690 \mathrm{~nm}$ was also measured, and subtracted from that of extracted dye.

Cell cycle analysis by flow cytometry. Cells were rinsed with ice-cold phosphate buffered saline (PBS), trypsinized, and resuspended in $0.3 \mathrm{ml}$ of PBS. They were then fixed and permeabilized by addition of $0.7 \mathrm{ml}$ of ethanol. After a brief wash, the cells were gently resuspended in $1 \mathrm{ml}$ of propidium iodide (PI) stain solution $(40 \mu \mathrm{g} / \mathrm{ml}$ propidium iodide, $100 \mu \mathrm{g} / \mathrm{ml}$ RNase A in PBS), and incubated at room temperature for $30 \mathrm{~min}$ before analysis on a FACScan flow cytometer (Becton-Dickinson, CA).

Glucose-6-phosphate dehydrogenase (G6PD) activity assay. G6PD activity was measured spectrophotometrically at $340 \mathrm{~nm}$ by the reduction of $\mathrm{NADP}^{+}$in the presence of glucose-6phosphate as described (32). In brief, cells were treated with 100 or $200 \mu \mathrm{M}$ of DHEA for indicated period; rapidly rinsed twice with $\mathrm{PBS}$; and collected in $1 \mathrm{ml}$ of extraction buffer [20 mM Tris- $\mathrm{HCl}$ ( $\mathrm{pH} 7.5$ ), $3 \mathrm{mM} \mathrm{MgCl}_{2}, 1 \mathrm{mM}$ EDTA, $0.02 \%(\mathrm{w} / \mathrm{v}) \beta$-mercaptoethanol, and $1 \mathrm{mM} \varepsilon$-amino-n-caproic acid). They were then chilled immediately in an ice bath, and disrupted by sonication. The resulting lysate was cleared by centrifugation at $12000 \mathrm{x} \mathrm{g}$ at $4^{\circ} \mathrm{C}$ for $20 \mathrm{~min}$, and the supernatant was used for the assay. A typical assay mixture consisted of $50 \mu \mathrm{g}$ of protein in $1 \mathrm{ml}$ of assay buffer $(50 \mathrm{mM}$ Tris- $\mathrm{HCl}$ ( $\mathrm{pH} 8.0$ ), $50 \mathrm{mM} \mathrm{MgCl}_{2}, 4 \mathrm{mM} \mathrm{NADP}{ }^{+}, 4 \mathrm{mM}$ glucose-6-phosphate). Change in absorbance at $340 \mathrm{~nm}$ was monitored spectrophotometrically.

Assessment of mitochondrial membrane potential $\Delta \Psi m$. The mitochondrial membrane potential was determined using the cationic, lipophilic dye JC-1 (5,5',6,6'-tetrachloro-1,1',3,3'tetraethylbenzimidazolocarbocyanine iodide) (Molecular Probes, Eugene, OR), as described elsewhere (33). In brief, about $5 \times 10^{5}$ cells were incubated with $0.5 \mu \mathrm{M} \mathrm{JC}-1$ in culture medium at $37^{\circ} \mathrm{C}$. After $60 \mathrm{~min}$, the adherent cell layer was then washed three times with PBS and dislodged with TrypsinEDTA. Cells were collected in $2 \%$ BSA/PBS, washed twice by centrifugation, and resuspended in $0.3 \mathrm{ml}$ of $2 \% \mathrm{BSA} / \mathrm{PBS}$ for analysis using a Becton-Dickinson FACScan. JC-1 monomers emit at $527 \mathrm{~nm}$ (FL1 channel), and J-aggregates emit at $590 \mathrm{~nm}$ (FL2 channel). Cytometer settings were optimized for green (FL1) and red (FL2) fluorescence, and the data were analyzed with CellQuest software. The ratio of the mean fluorescence intensity of FL2 channel to that of FL1 channel was then calculated. For confocal microscopy, cells were grown on glass bottom culture dish (MatTek, MA, USA). They were loaded with $0.5 \mu \mathrm{M} \mathrm{JC}-1$ under condition as described above, and counterstained with $5 \mu \mathrm{g} / \mathrm{ml}$ of Hoechst 3334210 min before examination under Leica TCS SP2 MP system (Leica Microsystems, Mannheim, Germany). Confocal fluorescence images of JC-1 labeled cells were obtained using HCX PL-APO CS 100x1.40 NA oil immersion objective. During scanning of JC-1 monomeric form, we used $488 \mathrm{~nm}$ excitation line of argon laser, triple-dichroic beam splitter (TD 488/543/633) and an emission window set at 500-540 nm. During scanning of JC-1 aggregated form, we used $543 \mathrm{~nm}$ excitation line of $\mathrm{He}-\mathrm{Ne}$ laser, triple-dichroic beam splitter (TD 488/543/633) and an emission window set at 580-620 nm. For scanning of Hoechst dye, we used a fiber coupling system equipped with a Ti:Sapphire laser (model Millenia/Tsunami; Spectra-Physics; Mountain View, CA, USA), which provides a pulse repetition rate at $82 \mathrm{MHz}$, a laser pulse width of $1.2 \mathrm{ps}$, a spectral bandwidth of $1 \mathrm{~nm}$, and an object pulse width of $1.3 \mathrm{ps}$ ). Wavelength at $800 \mathrm{~nm}$ was selected for illumination. The images were analyzed with Leica LCS software.

ATP determination. Cells were harvested by scraping, washed with PBS twice, and resuspended in $100 \mu \mathrm{l}$ of $0.1 \mathrm{M} \mathrm{NaOH}$. The cell lysate was neutralized with $100 \mu 1$ of $0.1 \mathrm{M} \mathrm{HCl}$, and was centrifuged at $12000 \mathrm{x}$ g at $4^{\circ} \mathrm{C}$ for $15 \mathrm{~min}$. Supernatant was retained, and its protein concentration was measured using Bio-Rad Assay (Bio-Rad Laboratories, Hercules, CA). Quantification of ATP was performed with ATP determination kit (Molecular Probes). Of the cleared lysate $500 \mathrm{ng}$ was added to $100 \mu \mathrm{l}$ of assay buffer (25 mM Tricine (pH 7.8), $5 \mathrm{mM} \mathrm{MgSO}_{4}, 0.1 \mathrm{mM}$ ethylenediaminetetraacetic acid, $1 \mathrm{mM}$ dithiothreitol, $0.5 \mathrm{mM}$ D-luciferin and $1.25 \mu \mathrm{g} / \mathrm{ml}$ of luciferase). The luminescence was detected using a microplate luminometer. A standard curve was prepared with ATP standard solutions. The concentration of sample was determined by interpolation, and its total amount was calculated accordingly. 
Table I. Primers used in the present study.

\begin{tabular}{|c|c|c|c|}
\hline Gene & Primer orientation & Sequence & Amplicon size (bp) \\
\hline \multirow[t]{2}{*}{ NDUFA9 } & Forward & 5'-CAGATTGTTCCTCCCATTCC-3' & 114 \\
\hline & Reverse & 5'-TGCATCCGCTCCACTTTATC-3' & \\
\hline \multirow[t]{2}{*}{ SDHA } & Forward & 5'-GCATTTCTACGACACCGTGA-3' & 72 \\
\hline & Reverse & 5'-TGCTCCGTCATGTAGTGGAT-3' & \\
\hline \multirow[t]{2}{*}{ UQCRFS1 } & Forward & 5'-TTCCAGCATGAGTGCTTCTG-3' & 86 \\
\hline & Reverse & 5'-CCATGTTCTTGCCTTCTGGA-3' & \\
\hline \multirow[t]{2}{*}{ COX5A } & Forward & 5'-TATCCAGTCAGTTCGCTGCT-3' & 100 \\
\hline & Reverse & 5'-GGCATCTATATCTGGCTTGTTG-3' & \\
\hline \multirow[t]{2}{*}{ ATP5O } & Forward & 5'-TGCGATGCTTCAGTACCTCT-3' & 87 \\
\hline & Reverse & 5'-CATAGCGACCTTCAATACCG-3' & \\
\hline \multirow[t]{2}{*}{ GAPDH } & Forward & 5'-TGTTCGTCATGGGTGTGAAC-3' & 66 \\
\hline & Reverse & 5'-AGGAGGCATTGCTGATGATCT-3' & \\
\hline
\end{tabular}

Determination of mitochondrial gene expression by reverse transcription-polymerase chain reaction $(R T-P C R)$. Total RNA from about $1 \times 10^{6}$ cells, which had been treated with DHEA, was extracted with TRIzol (Invitrogen) according to the manufacturer's instructions. Total RNA (1 $\mu \mathrm{g})$ was reverse-transcribed into cDNA using SuperScript First-Strand Synthesis kit (Invitrogen). One $\mu 1$ of a 1:100-dilution of the cDNA reaction was amplified with respective forward and reverse primers for NADH dehydrogenase (ubiquinone) 1 alpha subcomplex 9 (NDUFA9); succinate dehydrogenase complex subunit A (SDHA); ubiquinol-cytochrome c reductase Rieske iron-sulfur polypeptide 1 (UQCRFS1); cytochrome c oxidase subunit Va (COX5A); ATP synthase oligomycin sensitivity conferral protein (ATP5O); and glyceraldehyde 3phosphate dehydrogenase (GAPDH). The sequences of forward and reverse primers used are listed in Table I. The PCR reaction contains, in addition to template cDNA, $10 \mathrm{mM}$ Tris- $\mathrm{HCl}$ ( $\mathrm{pH} 8.3$ ), $50 \mathrm{mM} \mathrm{KCl}, 2.5 \mathrm{mM} \mathrm{MgCl}_{2}, 200 \mu \mathrm{M}$ dATP, $200 \mu \mathrm{M}$ dTTP, $200 \mu \mathrm{M}$ dGTP, $200 \mu \mathrm{M}$ dCTP, 25 pmol of forward and reverse primers, and 1.25 U AmpliTaq Gold enzyme. Quantitative PCR was performed with SYBR ${ }^{\circledR}$ Green PCR Master Mix (Applied Biosystem, Foster City, CA), according to the manufacturer's instructions. All PCR reactions were performed under the same thermal cycling conditions: $95^{\circ} \mathrm{C}, 10 \mathrm{~min} ; 30$ cycles of $95^{\circ} \mathrm{C}, 30 \mathrm{sec} ; 62^{\circ} \mathrm{C}$, $30 \mathrm{sec}$; and $72^{\circ} \mathrm{C}, 30 \mathrm{sec}$.

Western blotting. The cells were rinsed with cold PBS, scraped and collected by centrifugation. They were immediately lysed in lysis buffer $[20 \mathrm{mM}$ Tris- $\mathrm{HCl}(\mathrm{pH} 8.0), 1 \%$ Triton $\mathrm{X}-100,137 \mathrm{mM} \mathrm{NaCl}, 1.5 \mathrm{mM} \mathrm{MgCl}{ }_{2}, 10 \%$ glycerol, $1 \mathrm{mM}$ EGTA, $1 \mathrm{mM} \mathrm{NaF}, 1 \mathrm{mM} \mathrm{Na} \mathrm{VO}_{4}, 10 \mathrm{mM}$ ß-glycerophosphate, $1 \mathrm{mM}$ phenylmethylsulfonyl fluoride, $1 \mu \mathrm{g} / \mathrm{ml}$ leupeptin, $1 \mu \mathrm{g} / \mathrm{ml}$ aprotinin]. Protein concentration of the lysate was determined by Bio-Rad Assay (Bio-Rad). The sample was analyzed by SDS-PAGE and immunoblotting with antibodies to $\mathrm{pRb}$ (BD Sciences Pharmingen, San Diego, CA) and actin (Santa Cruz Biotechnology, CA) as previously described (34).

Statistical analysis. Results are expressed as mean \pm SD. Where appropriate, data were analyzed by analysis of variance (ANOVA) and t-test. p-values of $<0.05$ were considered significant.

\section{Results}

DHEA inhibits growth of Hep G2 cells. When DHEA was added to Hep G2 cells, cell growth evaluated by neutral red assay was significantly inhibited in dose- and time-dependent manner (Fig. 1A). Upon treatment with $200 \mu \mathrm{M}$ DHEA for $48 \mathrm{~h}$, cells showed significant $(\sim 47 \%)$ reduction in growth rate. Increasing the treatment time to $72 \mathrm{~h}$ further reduced the growth rate by about 20 and $60 \%$ in 100 and $200 \mu$ M DHEAtreated cells, respectively. Complete growth arrest resulted following 96-h treatment with $200 \mu \mathrm{M}$ DHEA.

The DHEA-induced growth stagnation in Hep G2 cells was characterized by the cell cycle arrest at G1 phase (Fig. 1B). As DHEA concentration reached $200 \mu \mathrm{M}$, the percentage of G1 cells significantly increased $(83.93 \pm 3.60 \%$ in treatment group versus $55.73 \pm 3.25 \%$ in control group, $\mathrm{p}<0.05$ ), whilst the percentage of $\mathrm{S}$ cells was greatly reduced $(7.50 \pm 3.15 \%$ in treatment group versus $37.13 \pm 3.30 \%$ in control group, $\mathrm{p}<0.05$ ). Such change in cell cycle profile correlates well with the dwindling proliferation rate of DHEA-treated cells.

G1 progression is controlled through activity of retinoblastoma $(\mathrm{Rb})$ protein, which exists in hypo- and hyperphosphorylated forms. The active, hypophosphorylated, but not the hyperphosphorylated, form binds to and inhibits E2F transcription factors necessary for G1 to S transition (35). 


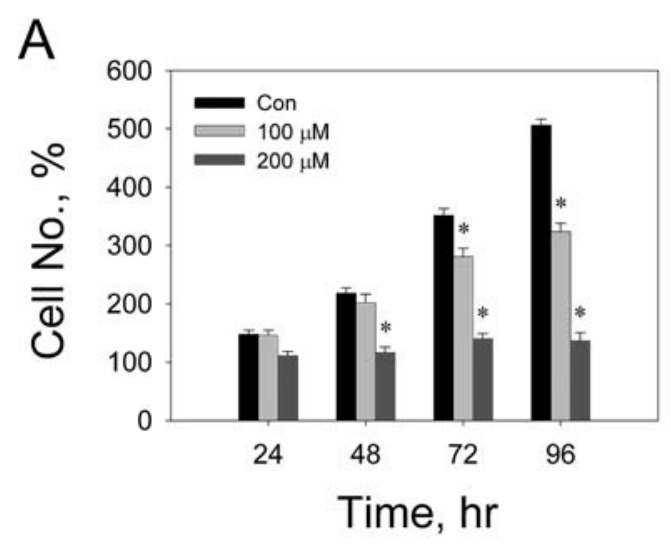

B
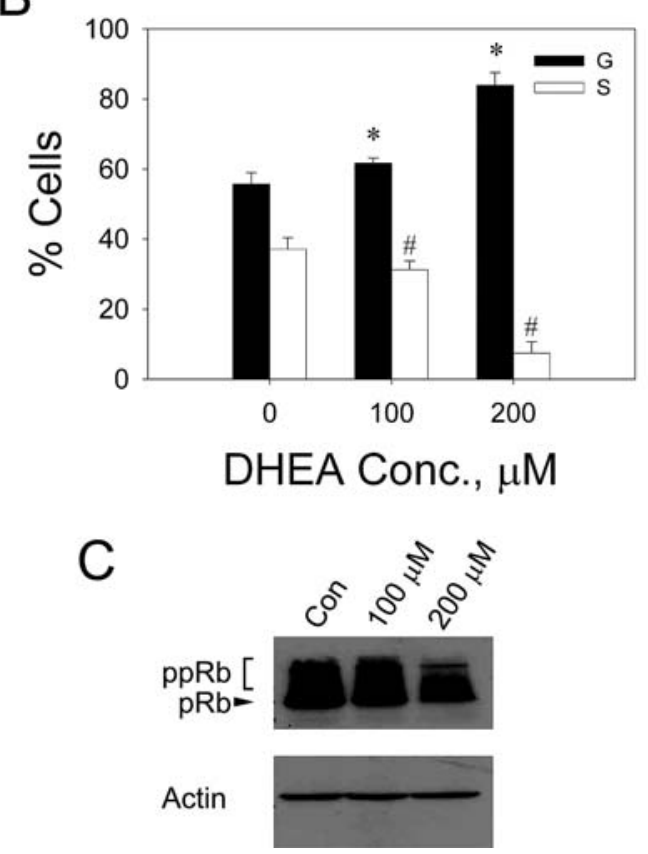

Figure 1. DHEA inhibited proliferation of Hep G2 cells. (A) About $2 \times 10^{5}$ cells were seeded overnight, and treated with 0,100 or $200 \mu \mathrm{M}$ DHEA for 24, 48, 72 or $96 \mathrm{~h}$. Cell numbers at indicated timepoints post-treatment was determined by neutral red assay. The absorbance values are expressed relative to that at $0 \mathrm{~h}$ (i.e. at the time of DHEA treatment). Results are mean \pm $\mathrm{SD}, \mathrm{n}=3$. ${ }^{*} \mathrm{p}<0.05$ vs. the untreated control at $0 \mathrm{~h}$. (B) DHEA-treated cells exhibited growth arrest in $\mathrm{G} 1$ phase. Cells were treated with 0,100 or $200 \mu \mathrm{M}$ DHEA for $48 \mathrm{~h}$, and harvested for cell cycle analysis. The percentages of cells in different phases of cell cycle were quantified using Modfit software (Becton-Dickinson). The percentages of cells in G1 (G) and S (S) phase are shown here. Results are mean $\pm \mathrm{SD}, \mathrm{n}=3$. ${ }^{*} \mathrm{p}<0.05 ;{ }^{*} \mathrm{p}<0.05$ vs. G1 and $\mathrm{S}$ phase cells in the untreated control, respectively. (C) Expression of $\mathrm{Rb}$ protein in DHEA-treated cells. Cells were treated with indicated concentrations of DHEA, and harvested $48 \mathrm{~h}$ later. Cell lysates were separated by SDS-PAGE and analyzed with anti-Rb antibodies by Western blotting. It should be noted that the anti-Rb antibody recognizes both the hypo- $(\mathrm{pRb})$ and hyperphosphorylated $(\mathrm{ppRb})$ forms. The results shown here are representative of at least three experiments.

After 48-h treatment with DHEA, the level of hyperphosphorylated $\mathrm{Rb}$ decreased in dose-dependent manner (Fig. 1C). Such results are consistent with the growth kinetics of DHEA-treated cells.

DHEA does not inhibit G6PD. To test the possibility that DHEA suppresses cell proliferation via inhibition of G6PD, we evaluated the effect of DHEA on G6PD activity. As shown in Fig. 2, DHEA increased G6PD activity in a dose-dependent

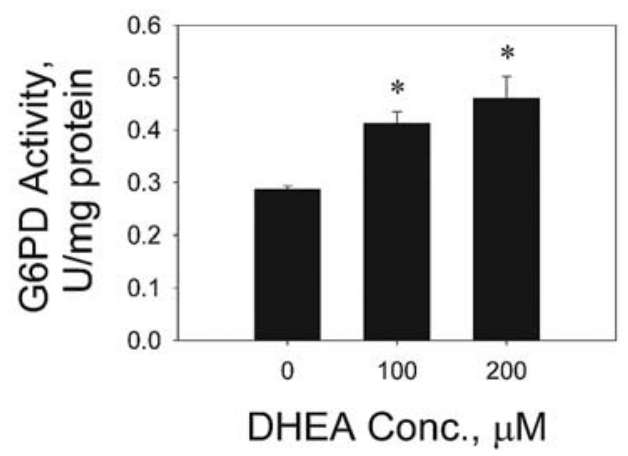

Figure 2. Changes in G6PD activities of Hep G2 cells upon DHEA treatment. Cells were treated with indicated concentrations of DHEA for $48 \mathrm{~h}$, and harvested for G6PD activity assay. G6PD activity is given in $\mathrm{U} / \mathrm{mg}$ of protein in cell lysate. Results are mean $\pm \mathrm{SD}, \mathrm{n}=6$. ${ }^{*} \mathrm{p}<0.05$ vs. the untreated control.

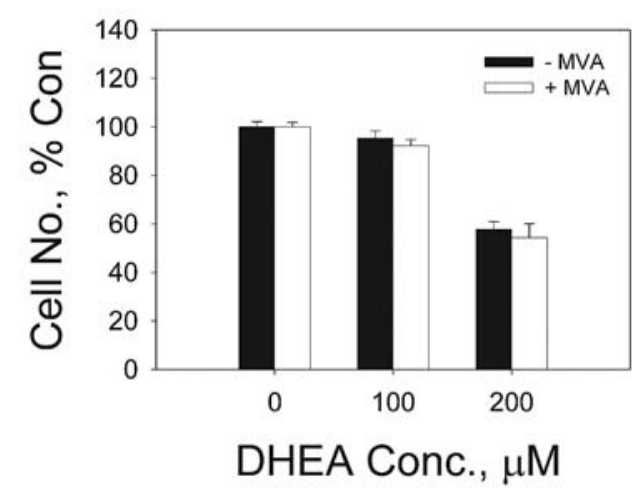

Figure 3. MVA did not restore proliferation of DHEA-treated cells. Cells were treated with indicated concentrations of DHEA for $48 \mathrm{~h}$ in the presence $(+M V A)$ or absence $(-M V A)$ of 2 mM MVA. Cell numbers were determined as described in the legend of Fig. 1, and are expressed relative to that with neither DHEA nor MVA treatment (Con). Results are mean $\pm \mathrm{SD}, \mathrm{n}=3$.

manner. The G6PD activity in Hep G2 cells increased by 44 and $61 \%$ after treatment with $100 \mu \mathrm{M}$ and $200 \mu \mathrm{M}$ DHEA, respectively. It is unlikely that DHEA effects via inhibition of G6PD.

DHEA does not affect the cholesterol biosynthetic pathway. It is possible that DHEA may exert its growth suppressive effects via inhibition of HMGR. To test such possibility, we treated DHEA-treated cells with MVA, the immediate product of HMGR, and assessed whether MVA would restore cell growth. As shown in Fig. 3, the addition of 2 mM MVA to culture medium did not affect cell growth at DHEA concentration up to $200 \mu \mathrm{M}$. Our findings suggest that DHEA does not act by inhibiting HMGR and cholesterol biosynthetic pathway.

Mitochondrial dysfunction and change in bioenergetic metabolism accompanies growth inhibition by DHEA. To explore the possibility that DHEA causes mitochondrial dysfunction and change in bioenergetic metabolism, we employed a flow cytometric method to assess mitochondrial membrane potential $\Delta \Psi \mathrm{m}$. As shown in Fig. 4 , there was a significant drop in $\Delta \Psi \mathrm{m}$ after treatment with DHEA. The $\Delta \Psi \mathrm{m}$ in cells treated with $100 \mu \mathrm{M}$ DHEA was reduced by 


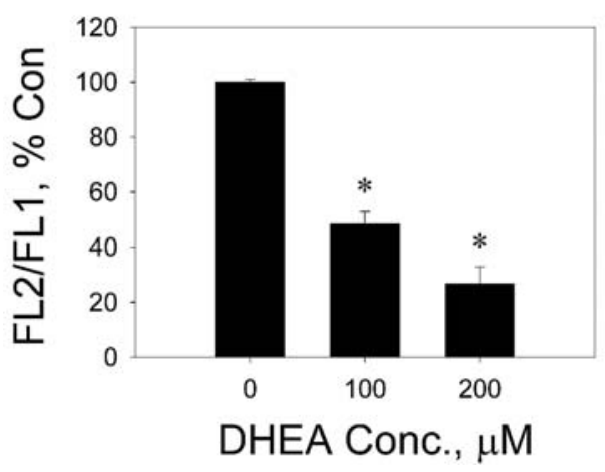

Figure 4. DHEA induced a reduction in $\Delta \Psi \mathrm{m}$. After 48 -h treatment with indicated concentrations of DHEA, cells were stained with JC-1 dye, and analyzed by flow cytometry. The ratio of mean fluorescence intensity of FL2 channel to that of FL1 channel (FL2/FL1) was calculated, and is expressed relative to that of untreated cells (Con). Results are mean \pm SD, $\mathrm{n}=6$. ${ }^{*} \mathrm{p}<0.05$ vs. the untreated control.

$50 \%$. An increase in DHEA concentration to $200 \mu \mathrm{M}$ further reduced it to $26.74 \pm 6.13 \%$ of that of control. Consistent with the flow cytometric method, the confocal fluorescence micrograph shows that control cells exhibited JC-1 fluorescence heterogeneity at mitochondrial level, as mitochondria appeared simultaneously red and green (Fig. 5D). After incubation with $100 \mu \mathrm{M}$ DHEA, mitochondrial depolarization (i.e. the decline in $\Delta \Psi \mathrm{m})$ caused significant reduction in red fluorescence ( $\mathrm{J}$ aggregate of JC-1) (Fig. 5F), and enhancement of green fluorescence (monomeric form of JC-1) (Fig. 5E). As the DHEA concentration increased to $200 \mu \mathrm{M}$, the red fluorescence was barely detectable (Fig. 5J), and only green fluorescence was visible (Fig. 5I).

The mitochondrial morphology was also affected by DHEA treatment. Mitochondria are pleomorphic organelles. Depending on cell cycle stage and metabolic state, their morphology ranges from short, round or ovoid structure (classified as fragmented) to long, branched or interconnected mitochondria (classified as reticular). In untreated cells, mitochondria were elongated tubular structures, which formed a reticulum (Fig. 5D). After addition of $100 \mu \mathrm{M}$ DHEA for $48 \mathrm{~h}$, the reticulum began to disrupt, yielding a number of ovoid organelles (Fig. 5H). All mitochondria underwent such changes as the DHEA dosage increased (Fig. 5L). The fragmented mitochondria tended to form clusters. The morphologic changes, together with mitochondrial depolarization, suggest the change in functional state of mitochondria following DHEA treatment.
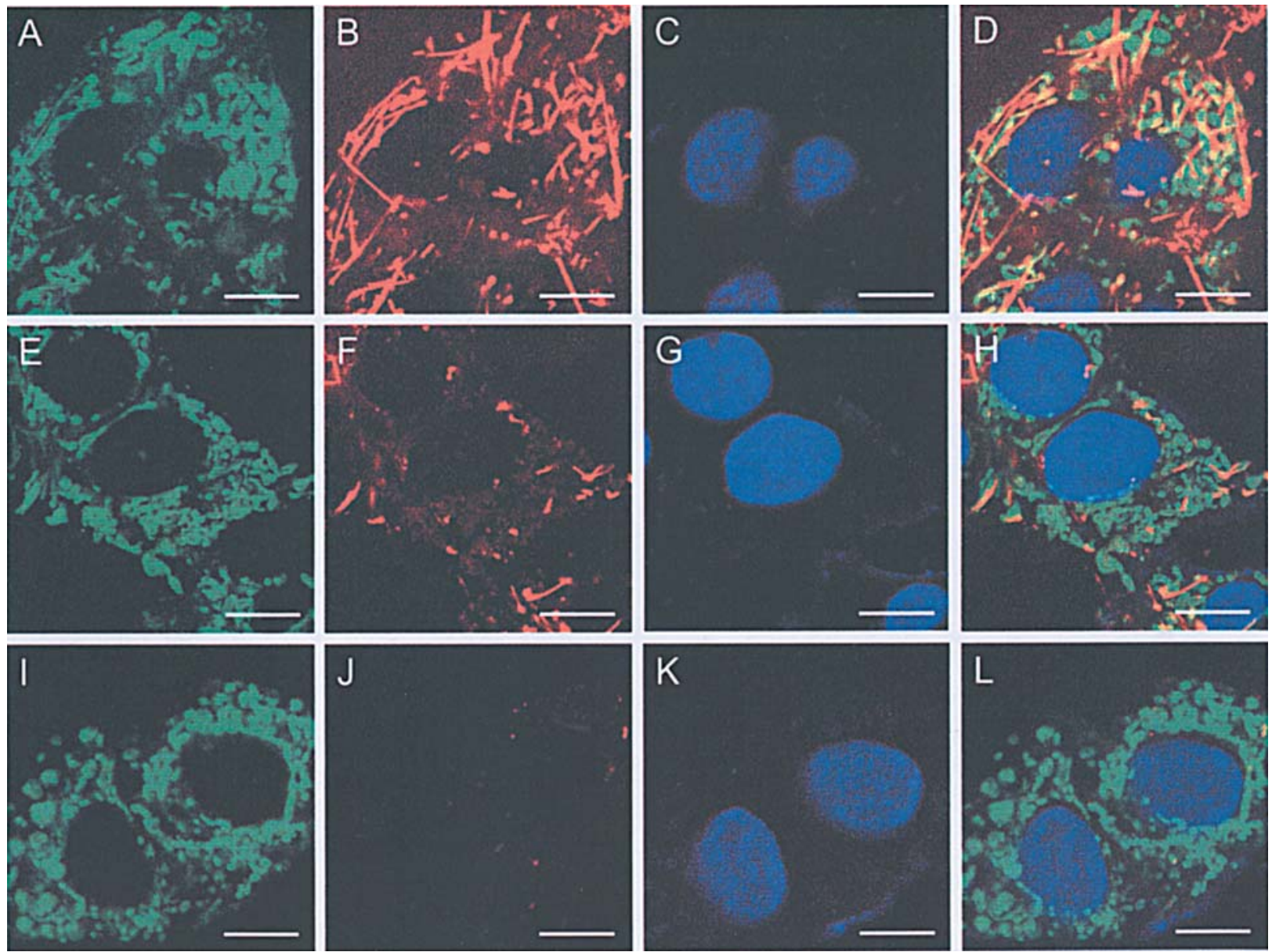

Figure 5. Mitochondrial depolarization was accompanied by morphologic changes in DHEA-treated cells. Cells were un- (A-D) or treated with 100 (E-H) or $200 \mu \mathrm{M}$ DHEA (I-L) for $48 \mathrm{~h}$. Cell were stained with JC-1 and Hoechst 33342 dyes, and confocal micrographs were taken. Intracellular distribution of JC-1 monomer (A, E and I) and J-aggregate (B, F and J) is indicative of $\Delta \Psi \mathrm{m}$ in cells with or without DHEA treatment. Nuclear morphology of these cells is shown $(\mathrm{C}, \mathrm{G}$ and $\mathrm{K})$. The corresponding images are overlaid (D, H and L). The photographs shown here are representative of three experiments. Scale bar, $10 \mu \mathrm{m}$. 


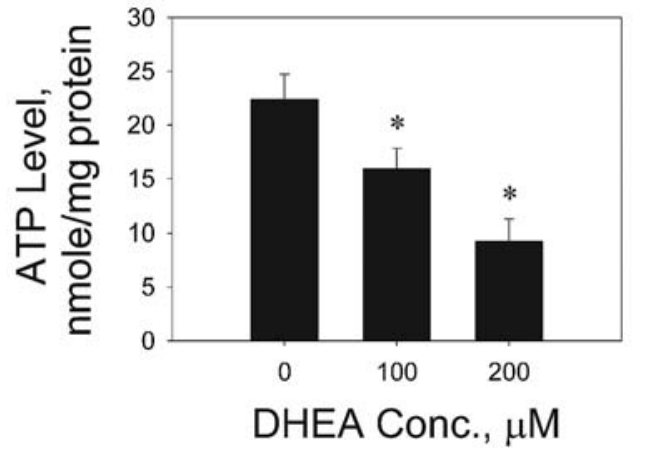

Figure 6. ATP depletion in Hep G2 cells upon DHEA treatment. Cells were treated with indicated concentrations of DHEA for $48 \mathrm{~h}$. Their ATP levels were measured, and is given as nmole/mg of protein in cell lysate. Results are mean $\pm \mathrm{SD}, \mathrm{n}=3 .{ }^{*} \mathrm{p}<0.05$ vs. the untreated control.

DHEA-induced mitochondrial dysfunction was accompanied with depletion of cellular energy reserve. As shown in Fig. 6, Hep G2 cells had their ATP level reduced by 30 and $60 \%$, respectively after incubation with 100 and $200 \mu \mathrm{M}$ DHEA for $48 \mathrm{~h}$.

Molecular changes accompanying DHEA-induced mitochondrial dysfunction. To examine the molecular changes accompanying DHEA-induced mitochondrial dysfunction, we quantified expression of several nucleus-encoded mitochondrial genes by RT-PCR and quantitative PCR. The genes under examination correspond to subunits of different mitochondrial respiratory complexes, and include NDUFA9 (complex I), SDHA (complex II), UQCRFS1 (complex III),

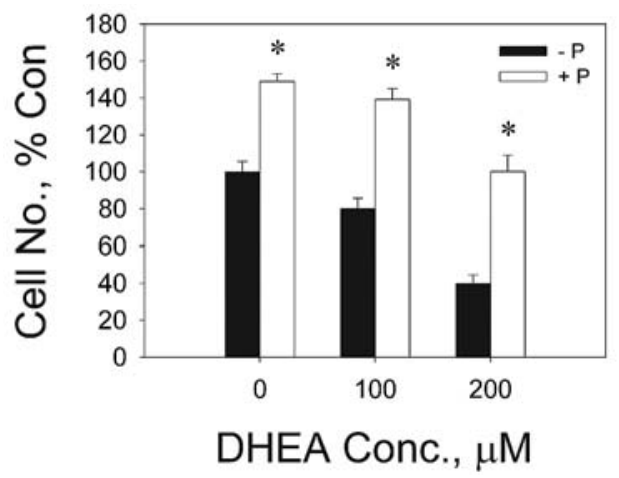

Figure 8. Effect of pyruvate supplementation on DHEA-induced cell growth inhibition. Cells were treated with indicated concentrations of DHEA for $72 \mathrm{~h}$ in the presence $(+P)$ or absence $(-P)$ of $1 \mathrm{mM}$ pyruvate. Cell numbers were determined as described in the legend of Fig. 1, and are expressed relative to that with neither DHEA nor pyruvate treatment (Con). Results are mean \pm $\mathrm{SD}, \mathrm{n}=3$. ${ }^{*} \mathrm{p}<0.05 \mathrm{vs}$. the corresponding cell sample without pyruvate treatment.

COX5A (complex IV) and ATP5O (complex V). Significantly reduced expression of all these genes was observed in DHEAtreated cells. Such decline displayed dose-dependence (Fig. 7). Of note, expression of SDHA and UQCRFS1 was the most affected. Abundance of SDHA and UQCRFS1 transcripts decreased by over 70 and $65 \%$ following a 48 -h treatment with $200 \mu \mathrm{M}$ DHEA (Fig. 7B).

Pyruvate supplementation mitigates the growth suppressive effect of DHEA. Pyruvate supplementation has been used for enhancement of cellular energetics and mitochondrial functionality $(36,37)$. We investigated whether pyruvate

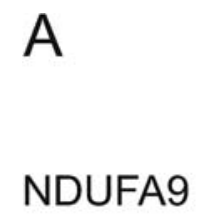

SDHA

UQCRFS1

COX5A

ATP5O

GAPDH
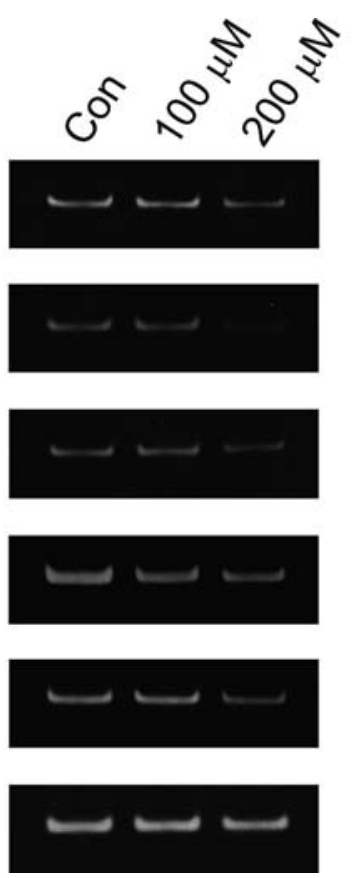

B

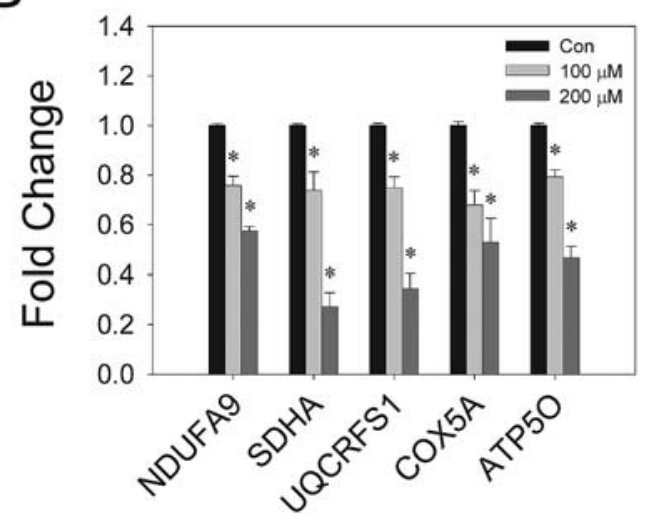

Figure 7. Expression of mitochondrion-associated genes in DHEA-treated cells. Cells were treated with indicated concentrations of DHEA for 48 h. Total RNA was extracted, and cDNA prepared. Expression of NDUFA9, SDHA, UQCRFS1, COX5A and ATP5O genes was quantified by RT-PCR and quantitative PCR. GAPDH served as a housekeeping control for RT-PCR, and for normalization purpose in quantitative PCR. (A) Electrophoretograms of RT-PCR products are shown. These are taken from one out of six experiments. (B). Transcript levels, determined by quantitative PCR, are represented as fold change relative to that of untreated control (Con). Results are mean $\pm \mathrm{SD}, \mathrm{n}=6 .{ }^{*} \mathrm{p}<0.05$ vs. the untreated control. 
supplementation could reverse the growth inhibition by DHEA. Addition of $1 \mathrm{mM}$ pyruvate significantly enhanced the proliferation of untreated cells and those receiving treatment with $100 \mu \mathrm{M}$ DHEA (Fig. 8). More strikingly, pyruvate induced 2.5-fold increase in growth of cells which were treated with $200 \mu \mathrm{M}$ DHEA. These findings suggest that the pyruvate supplementation alleviates the growth inhibition by DHEA.

\section{Discussion}

DHEA is known to have anti-proliferative and anti-neoplastic effects in various cell and animal models (12-20). The underlying mechanism remains unclear. In the present study, we show that DHEA dose-dependently inhibited proliferation, leading to G1 arrest in Hep G2 cells (Fig. 1). This effect was not attributed to either inhibition of G6PD or HMGR (Figs. 2 and 3). Instead, DHEA caused changes in mitochondrial morphology and function (Figs. 4 and 5), as well as depletion of cellular ATP (Fig. 6). Mitochondrial dysfunction was associated with reduced expression of nucleusencoded mitochondrial genes (Fig. 7). Treatment with pyruvate alleviates the growth suppressive effect of DHEA (Fig. 8). Taken together, our findings suggest that DHEA causes malfunctioning of mitochondria, probably leading to growth cessation.

Previous studies have suggested that DHEA acts as noncompetitive G6PD inhibitor $(38,39)$, and might inhibit cell growth through diminished production of ribose-5-phosphate, a precursor of nucleotide biosynthesis $(21,40)$. Several lines of evidence suggest that G6PD inhibition does not account for the growth inhibition of Hep G2 cells. The conclusion in favor of the involvement of G6PD in DHEA-induced growth inhibition was based on the measurement of G6PD activity of cell lysate in the presence of exogenously added DHEA $(21,41)$. Contrary to these reports, we found that the G6PD activity in Hep G2 cells actually increased rather than decreased after a 48-h treatment with DHEA (Fig. 2). In another experimental system, we measured the G6PD activity in erythrocytes at various timepoints after DHEA addition. It was observed that erythrocytic G6PD activity declined transiently, but returned to its original level within $2 \mathrm{~h}$ (our unpublished data). In addition, the anti-proliferative abilities of DHEA analogues do not correlate with their G6PD inhibitory activities [our unpublished data; (23)]. Moreover, DHEA still inhibits growth of G6PD-knockdown human fibroblast and Hep G2, suggesting the existence of molecular target(s) other than G6PD (our unpublished data). All these findings suggest that DHEA does not suppress growth of Hep G2 cells by G6PD inhibition.

Another mechanism to account for anti-proliferative effect of DHEA may be inhibition of HMGR (42). HMGR is the rate-limiting enzyme in the biosynthesis of farnesyl diphosphate and cholesterol. Inhibition of this enzyme not only affects cholesterol biosynthesis, but also reduces farnesylation of Ras and MAPK signaling. Inhibition of MAPK signaling can lead to growth cessation. However, in the present study, addition of MVA to culture did not relieve DHEA-induced growth inhibition. It is unlikely that HMGR acts as molecular target of DHEA.
Our findings that DHEA elicited functional and morphologic changes in mitochondria are intriguing. The growth arrest of Hep G2 cells was accompanied by fission of reticular mitochondria. Fission of mitochondria is believed to be a morphologic transition, which occurs as part of an apoptotic program (43). In the present study, mitochondrial fragmentation was unlikely to be linked to apoptosis, as chromatin clumping did not occur upon DHEA treatment (Fig. 5). In addition, no sub-G1 population, taken as a measure of apoptotic body formation, was ever detected. Generally speaking, mitochondria form a highly dynamic structure capable of fusion and fission (44). These two processes occur concurrently in a balanced ratio. Depending on external cues and cell state, the balance can be shifted to one side or another. The changes in mitochondrial morphology accompanying growth arrest are not unprecedented. The reticular mitochondria of Saccharomycetes cerevisiae is fragmented, giving rise to 30-50 mitochondria per cell during stationery growth phase (45). Serum-starved osteosarcoma cells have more fragmented mitochondria than their proliferating counterparts (46). Mammalian cells lacking mitofusins exhibit mitochondrial fragmentation and poor cell growth (47). Probably, the morphology of mitochondria in DHEA-treated cells is indicative of their malfunctioning, that is, mitochondrial depolarization (Fig. 4). Similar observations have been made on mitofusin-deficient cells (47). Apparently, there exists a close relationship between mitochondrial morphology and their functional states.

Mitochondrial dysfunction was associated with reduced expression of nuclear genes encoding various respiratory complex subunits (Fig. 7). It is currently unknown whether DHEA represses transcription of specific mitochondrionrelated genes, or induces a global change in expression of these genes. Experiments are under way to test these possibilities. Despite these uncertainties, DHEA-induced repression of mitochondrion-related genes provides a novel mechanism for concomitant changes in mitochondrial functions. For instance, decreased SDHA transcription may lead to decreased complex II assembly, and consequently the electron entry at this complex. Alternative, non-exclusive mechanisms may also operate. DHEA has been found to inhibit complex I activity and aspartate-malate shuttle in vivo $(48,49)$; DHEA may induce changes in composition (50), and peroxidation of mitochondrial membrane lipid (51). Regardless of the mechanisms involved, DHEA-induced mitochondrial function may lead to ATP depletion (Fig. 6), and in turn the growth cessation of Hep G2. Pyruvate has been used for enhancing mitochondrial function, through either increased metabolite supply (36), or increased mitochondrial biogenesis (37). The finding that pyruvate supplementation could relieve the growth suppressive effect of DHEA supports the role of mitochondrion as downstream target of DHEA.

In conclusion, DHEA suppresses cell growth through inhibition of mitochondrial function and depletion of ATP. Conceivably, at least some of its anti-neoplastic effects may be due to interference with mitochondrial functions and bioenergetic metabolism. Understanding the mechanism(s) and downstream target(s) of DHEA is likely to pave way for novel cancer therapy. Cancer cells exhibits altered bioenergetic phenotypes, such as increased glycolysis and 
reduced OXPHOS activity, which have been exploited for therapeutic purpose. Compounds, like 3-bromopyruvate and 2-deoxyglucose, target the glucose metabolic pathway, and have been shown to have anti-tumor activity $(52,53)$. It has been recently reported that colon cancer cells with higher $\Delta \Psi \mathrm{m}$ display increased invasiveness (54). DHEA or analogues, which inhibit mitochondrial functions, may be used effectively as chemotherapeutic agents.

\section{Acknowledgements}

This work was supported by grants from Chang Gung University (CMRPD140041, CMRPG330723-III \& CMRPD33015), National Science Council of Taiwan (NSC95-2320-B-182A006, NSC95-2320-B-182-035-MY2, NSC95-2314-B-182-008 \& NSC95-2314-B-182-020) and the Ministry of Education of Taiwan (EMRPD EMRPD170581).

\section{References}

1. Parker CR Jr: Dehydroepiandrosterone and dehydroepiandrosterone sulfate production in the human adrenal during development and aging. Steroids 64: 640-647, 1999.

2. Yen SC and Laughlin GA: Aging and the adrenal cortex. Exp Gerontol 33: 897-910, 1998.

3. Cleary MP: The antiobesity effects of dehydroepiandrosterone in rats. Proc Soc Exp Biol Med 196: 8-16, 1991.

4. Mcintosh MK and Berdanier CD: Antiobesity effects of dehydroepiandrosterone are mediated by futile substrate cycling in hepatocytes of BHE/cdb rats. J Nutr 121: 2037-2043, 1991.

5. Coleman DL, Leiter EH and Schwizer RW: Therapeutic effects of dehydroepiandrosterone in diabetic mice. Diabetes 31: 830-833, 1982.

6. Coleman DL, Schwizer RW and Leiter EH: Effect of genetic background on the therapeutic effects of dehydroepiandrosterone in diabetes-obesity mutants and in aged normal mice. Diabetes 33: 26-32, 1984.

7. Gordon GB, Bush DE and Weisman HF: Reduction of atherosclerosis by administration of dehydroepiandrosterone. A study in the hypercholesterolemic New Zealand white rabbit with aortic intimal injury. J Clin Invest 82: 712-720, 1988.

8. Nafziger AN, Herrington DM and Bush TL: Dehydroepiandrosterone and dehydroepiandrosterone sulfate: their relation to cardiovascular disease. Epidemiol Rev 13: 267-293, 1991.

9. Wojtal K, Trojnar MK and Czuczwar SJ: Endogenous neuroprotective factors: neurosteroids. Pharmacol Rep 58: 335-340, 2006.

10. Zumoff B, Levin J, Rosenfeld RS, Markham M, Strain GW and Fukushima DK: Abnormal 24-h mean plasma concentrations of dehydroepiandrosterone and dehydroepiandrosterone sulfate in women with primary operable breast cancer. Cancer Res 41: 3360-3363, 1981.

11. Gordon GB, Helzlsouer KJ and Comstock GW: Serum levels of dehydroepiandrosterone and its sulfate and the risk of developing bladder cancer. Cancer Res 51: 1366-1369, 1991.

12. Hursting SD, Perkins SN, Haines DC, Ward JM and Phang JM: Chemoprevention of spontaneous tumorigenesis in p53-knockout mice. Cancer Res 55: 3949-3953, 1995.

13. Moore MA, Thamavit W, Ichihara A, Sato K and Ito N: Influence of dehydroepiandrosterone, diaminopropane and butylated hydroxyanisole treatment during the induction phase of rat liver nodular lesions in a short-term system. Carcinogenesis 7: 1059-1063, 1986.

14. Garcea R, Daino L, Pascale R, Frassetto S, Cozzolino P, Ruggiu ME and Feo F: Inhibition by dehydroepiandrosterone of liver preneoplastic foci formation in rats after initiation-selection in experimental carcinogenesis. Toxicol Pathol 15: 164-169, 1987.

15. Simile M, Pascale RM, De Miglio MR, Nufris A, Daino L, Seddaiu MA, Muroni MR, Rao KN and Feo F: Inhibition by dehydroepiandrosterone of growth and progression of persistent liver nodules in experimental rat liver carcinogenesis. Int J Cancer 62: 210-215, 1995.
16. Nyce JW, Magee PN, Hard GC and Schwartz AG: Inhibition of 1,2-dimethylhydrazine-induced colon tumorigenesis in Balb/c mice by dehydroepiandrosterone. Carcinogenesis 5: 57-62, 1984.

17. Schwartz AG and Tannen RH: Inhibition of 7,12-dimethylbenz[a]-anthracene- and urethane-induced lung tumor formation in $\mathrm{A} / \mathrm{J}$ mice by long term treatment with dehydroepiandrosterone. Carcinogenesis 2: 1335-1337, 1981.

18. Ratko TA, Detrisac CJ, Mehta RG, Kelloff GJ and Moon RC: Inhibition of rat mammary gland chemical carcinogenesis by dietary dehydroepiandrosterone or a fluorinated analogue of dehydroepiandrosterone. Cancer Res 51: 481-486, 1991.

19. Melvin WS, Boros LG, Muscarella P, Brandes JL, Johnson LA, Fisher WE, Schirmer WJ and Ellison EC: Dehydroepiandrosterone-sulfate inhibits pancreatic carcinoma cell proliferation in vivo and in vivo. Surgery 121: 392-397, 1997.

20. Rao MS and Subbarao V: Dehydroepiandrosterone inhibits DNA synthesis of rat hepatocytes induced by partial hepatectomy or mitogen (ciprofibrate). Cell Prolif 30: 1-5, 1997.

21. Tian WN, Braunstein LD, Pang J, Stuhlmeier KM, Xi QC, Tian X and Stanton R: Importance of glucose-6-phosphate dehydrogenase activity for cell growth. J Biol Chem 273: 10609-10617, 1998.

22. Boccuzzi G, Di-Monaco M, Brignardello E, Leonardi L, Gatto V, Pizzini A and Gallo M: Dehydroepiandrosterone antiestrogenic action through androgen receptor in MCF-7 human breast cancer cell line. Anticancer Res 13: 2267-2272, 1993.

23. Yoshida S, Honda A, Matsuzaki Y, Fukushima S, Tanaka N, Takagiwa A, Fujimoto Y, Miyazaki H and Salen G: Antiproliferative action of endogenous dehydroepiandrosterone metabolites on human cell lines. Steroids 68: 73-83, 2003.

24. Biaglow JE, Ayene IS, Koch CJ, Donahue J, Stamato TD and Tuttle SW: G6PD-deficient cells and the bioreduction of disulfides:effects of DHEA, GSH depletion and phenylarsine oxide. Biochem Biophys Res Commun 273: 846-852, 2000.

25. Ng HP, Wang YF, Lee CY and Hu ML: Toxicological and antioxidant effects of short-term dehydroepiandrosterone injection in young rats fed diets deficient or adequate in vitamin E. Food Chem Toxicol 37: 503-508, 1999.

26. Pascale RM, Simile MM, De Miglio MR, Nufris A, Seddaiu MA, Muroni MR, Danni O, Rao KN and Feo F: Inhibition of 3hydroxy-3-methyl glutaryl-CoA reductase activity and gene expression by dehydroepiandrosterone in preneoplastic liver nodules. Carcinogenesis 16: 1537-1542, 1995.

27. Schulz S, Klann RC, Schonfeld S and Nyce JW: Mechanisms of cell growth inhibition and cell cycle arrest in human colonic adenomas cells by dehydroepiandrosterone: role of isoprenoid biosynthesis. Cancer Res 52: 1372-1376, 1992.

28. Aoki K, Saito T, Satoh S, Mukasa K, Kaneshiro M, Kawasaki S, Okamura A and Sekihara H: Dehydroepiandrosterone suppresses the elevated hepatic glucose-6-phosphatase and fructose-1,6bisphosphatase activities in $\mathrm{C} 57 \mathrm{BL} / \mathrm{Ksj}-\mathrm{db} / \mathrm{db}$ mice. Comparison with Troglitazone. Diabetes 48: 1579-1585, 1999.

29. Yamashita R, Saito T, Satoh S, Aoki K, Kaburagi Y and Sekihara H: Effects of dehydroepiandrosterone on gluconeogenic enzymes and glucose uptake in human hepatoma cell line. Endocrine J 52: 727-733, 2005.

30. Nakashima N, Haji M, Sakai Y, Ono Y, Umeda F and Nawata H: Effect of dehydroepiandrosterone on glucose uptake in cultured human fibroblasts. Metabolism 44: 543-548, 1995.

31. Borenfreund $\mathrm{E}$ and Puerner JA: Toxicity determined in vivo by morphological alterations and neutral red absorption. Toxicol Lett 24: 119-124, 1985

32. Cheng ML, Ho HY, Wu YH and Chiu DTY: Glucose-6-phosphate dehydrogenase-deficient cells show an increased propensity for oxidant-induced senescence. Free Radic Biol Med 36: 580-591, 2004.

33. Ho HY, Cheng ML, Cheng PF and Chiu DTY: Low oxygen tension alleviates oxidative damage and delays cellular senescence in G6PD-deficient cells. Free Radic Res 41: 571-579, 2007.

34. Cheng ML, Ho HY, Huang YW, Lu FJ and Chiu DTY: Humic acid induces oxidative DNA damage, growth retardation, and apoptosis in human primary fibroblasts. Exp Biol Med 228: 413-423, 2003.

35. Chen PL, Scully P, Shew JY, Wang JY and Lee WH: Phosphorylation of the retinoblastoma gene product is modulated during the cell cycle and cellular differentiation. Cell 58: 1193-1198, 1989. 
36. Xu D and Finkel T: A role for mitochondria as potential regulators of cellular life span. Biochem Biophys Res Commun 294: 245-248, 2002.

37. Wilson L, Yang Q, Szustakowski JD, Gullicksen PS and Halse R: Pyruvate induces mitochondrial biogenesis by a PGC-1 $\alpha$-independent mechanism. Am J Physiol Cell Physiol 292: C1599-C1605, 2007.

38. Raineri R and Levy HR: On the specificity of steroid interaction with mammary glucose-6-phosphate dehydrogenase. Biochemistry 9: 2233-2243, 1970.

39. Gordon G, Mackow MC and Levy HR: On the mechanism of interaction of steroids with human glucose-6-phosphate dehydrogenase. Arch Biochem Biophys 318: 25-29, 1995.

40. Schwartz AG and Pashko LL: Mechanism of cancer preventive action of DHEA: role of glucose-6-phosphate dehydrogenase. Ann NY Acad Sci 774: 180-186, 1995.

41. Gordon GB, Newitt JA, Shantz LM, Weng DE and Talalay P: Inhibition of the conversion of 3T3 fibroblast clones to adipocytes by dehydroepiandrosterone and related anticarcinogenic steroids. Cancer Res 46: 3389-3395, 1986.

42. Matsuzaki Y and Honda A: Dehydroepiandrosterone and its derivative: potentially novel anti-proliferative and chemopreventive agents. Curr Pharm Des 12: 3411-3421, 2006.

43. Karbowski M and Youle RJ: Dynamics of mitochondrial morphology in healthy cells and during apoptosis. Cell Death Differ 10: 870-880, 2003.

44. Polyakov VY, Soukhomlinova MY and Fais D: Fusion, fragmentation, and fission of mitochondria. Biochemistry (Mosc) 68: 838-849, 2003.

45. Stevens BJ: Variation in number and volume of the mitochondria in yeast according to growth conditions. A study based on serial sectioning and computer graphics reconstitution. Biol Cell 28: 37-56, 1977.
46. Margineantu DH, Cox WG, Sundell L, Sherwood SW, Beechem JM and Capaldi RA: Cell cycle dependent morphology change and associated mitochondrial DNA redistribution in mitochondria of human cell lines. Mitochondrion 1: 425-435, 2002.

47. Chen $\mathrm{H}$ and Chan DC: Emerging functions of mammalian mitochondrial fusion and fission. Hum Mol Genet 14: R283-R289, 2005.

48. Safiulina D, Peet N, Seppet E, Zharkovsky A and Kaasik A: Dehydroepiandrosterone inhibits complex of the mitochondrial respiratory chain and is neurotoxic in vivo and in vivo. Toxicol Sci 93: 348-356, 2006.

49. Mohan PF and Cleary MP: Dehydroepiandrosterone and related steroids inhibit mitochondrial respiration in vivo. Int J Biochem 21: 1103-1107, 1989.

50. Katyare SS, Modi HR and Patel MA: Dehydroepiandrosterone treatment alters lipid/phospholipid profiles of rat brain and liver mitochondria. Curr Neurovasc Res 3: 273-279, 2006.

51. Swierczynski J and Mayer D: Dehydroepiandrosterone-induced lipid peroxidation in rat liver mitochondria. J Steroid Biochem Mol Biol 58: 599-603, 1996.

52. Maschek G, Savaraj N, Priebe W, Braunschweiger P, Hamilton K, Tidmarsh GF, De Young LR and Lampidis TJ: 2-Deoxy-Dglucose increases the efficacy of adriamycin and paclitaxel in human osteosarcoma and non-small cell lung cancers in vivo. Cancer Res 64: 31-34, 2004.

53. Geschwind JFH, Ko YH, Torbenson MS, Magee C and Pedersen PL: Novel therapy for liver cancer: direct intraarterial injection of a potent inhibitor of ATP production. Cancer Res 62: 3909-3913, 2002.

54. Heerdt BG, Houston MA and Augenlicht LH: The intrinsic mitochondrial membrane potential of colonic carcinoma cells is linked to the probability of tumor progression. Cancer Res 65: 9861-9867, 2005. 